\title{
Verzeichnis der Redner
}

Bachof S. 258, 279

Battis S. 263

Berka S. 94

Böckenförde S. 122

Bothe S. 267

Breuer S. 272

Burmeister S. 256, 285, 291

von Campenhausen S. 146

Ebsen S. 126

Fleiner-Gerster S. 300

Frotscher S. 277

Götz S. 265

Grimm S. 108

Häberle S. 114, 251

Haverkate S. 261

Hoffmann-Riem S. 129

H. P. Ipsen S. 254

Kisker S. 135

Krause S. 294

Kriele S. 94, 151

Lange S. 123

Löwer S. 291

Mantl S. 140

Maurer S. 280

H. Meyer S. 272, 276, 293

Öhlinger S. 296

Oldiges S. 275, 277

Oppermann S. 105

Partsch S. 127

Pirson S. 110

Püttner S. 283

Raschauer S. 269

Ress S. 288

Roellecke S. 113

Saladin S. 118

Soell S. 132, 134

Schachtschneider S. 136, 281, 293 
Schmidt-Jortzig S. 128

Scholler S. 116

Staff S. 124

Steiger S. 142

Steinberg S. 139

Stettner S. 117

Thieme S. 137

Thürer S. 100

Tomuschat S. 250, 303

Vogel S. 120, 134, 286, 291

Wahl S. 134

Zacher S. 111, 287, 303

Zuleeg S. 138, 260, 292 